\title{
Allergic airway inflammation induces a pro-secretory epithelial ion transport phenotype in mice
}

\author{
P. Anagnostopoulou, L. Dai, J. Schatterny, S. Hirtz, J. Duerr and M.A. Mall
}

ABSTRACT: The airway epithelium is a central effector tissue in allergic inflammation and Thelper cell (Th) type 2-driven epithelial responses, such as mucus hypersecretion contribute to airflow obstruction in allergic airway disease. Previous in vitro studies demonstrated that Th2 cytokines also act as potent modulators of epithelial ion transport and fluid secretion, but the in vivo effect of allergic inflammation on airway ion transport remains unknown.

We, therefore, induced allergic inflammation by intratracheal instillation of Aspergillus fumigatus extract or interleukin-13 in mice and determined effects on ion transport in native tracheal and bronchial tissues.

We demonstrate that allergic inflammation enhanced basal $\mathrm{Cl}^{-}$secretion in both airway regions and inhibited epithelial $\mathrm{Na}^{+}$channel (ENaC)-mediated $\mathrm{Na}^{+}$absorption and increased $\mathrm{Ca}^{2+}$ dependent $\mathrm{Cl}^{-}$secretion in bronchi. Allergen-induced alterations in bronchial ion transport were associated with reduced transcript levels of $\alpha-, \beta$ - and $\gamma \mathrm{ENaC}$, and were largely abrogated in signal transducer and activator of transcription (Stat) $6^{-/-}$mice.

Our studies demonstrate that Th2-dependent airway inflammation produced a pro-secretory ion transport phenotype in vivo, which was largely Stat6-dependent. These results suggest that Th2mediated fluid secretion may improve airway surface hydration and clearance of mucus that is hypersecreted in allergic airway diseases such as asthma, and identify epithelial Stat6 signalling as a potential therapeutic target to promote mucus hydration and airway clearance.

KEYWORDS: Allergic airway inflammation, epithelial sodium channel, interleukin-13, ion transport, mucociliary clearance, signal transducer and activator of transcription 6

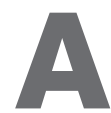

llergic airway diseases, such as asthma, belong to the most common chronic diseases in children and adults, but their pathogenesis remains incompletely understood [1]. The airway epithelium provides important protective functions and constitutes a central effector tissue in allergic airway disease. In healthy airways, the superficial respiratory epithelium acts as a barrier and provides coordinate regulation of mucus secretion, ciliary beating and airway surface liquid (ASL) volume, functions that are essential for effective mucociliary clearance (MCC) and protection of the lung from inhaled allergens, pathogens and other noxious agents [2-4]. A large body of evidence suggests that a T-helper cell (Th) type $1 / 2$ imbalance with a Th2-dominant response to inhaled allergens plays a critical role in the pathogenesis of allergic airway inflammation and identified the Th2 cytokine interleukin (IL)13 as a key effector molecule in this process $[1,5,6]$. Further studies demonstrated that IL-13, through binding to a common IL-4/IL-13 receptor complex and activation of signal transducer and activator of transcription (Stat)6 signalling, has direct effects on airway epithelial cells, including mucus hypersecretion, goblet cell metaplasia and airway hyperresponsiveness [7], key features contributing to airflow obstruction in the clinical syndrome of asthma.

In addition, more recent in vitro studies showed that IL-13 and the related Th2 cytokine IL-4 act as potent modulators of ion transport in cultured human bronchial epithelial cells, identifying another direct effect of these Th2 cytokines on the airway epithelium $[8,9]$. By active regulation of transepithelial ion transport, the airway epithelium maintains the thin film of liquid that covers airway surfaces and provides a lowviscosity layer essential for proper ciliary beating and MCC [3]. In this process, the amiloridesensitive epithelial $\mathrm{Na}^{+}$channel $(\mathrm{ENaC})$ is limiting for the absorption of $\mathrm{Na}^{+}$and osmotically

\section{AFFILIATIONS}

Division of Paediatric Pulmonology and Allergy and Cystic Fibrosis Center, Dept of Paediatrics III, University of Heidelberg, Heidelberg, Germany.

\section{CORRESPONDENCE}

M.A. Mall

Division of Paediatric Pulmonology and Cystic Fibrosis Center,

Dept of Paediatrics III

University of Heidelberg Im Neuenheimer Feld 430 69120 Heidelberg

Germany

E-mail: Marcus.Mall@med.uniheidelberg.de

Received:

Nov 132009

Accepted after revision:

April 122010

First published online:

April 222010 
a)
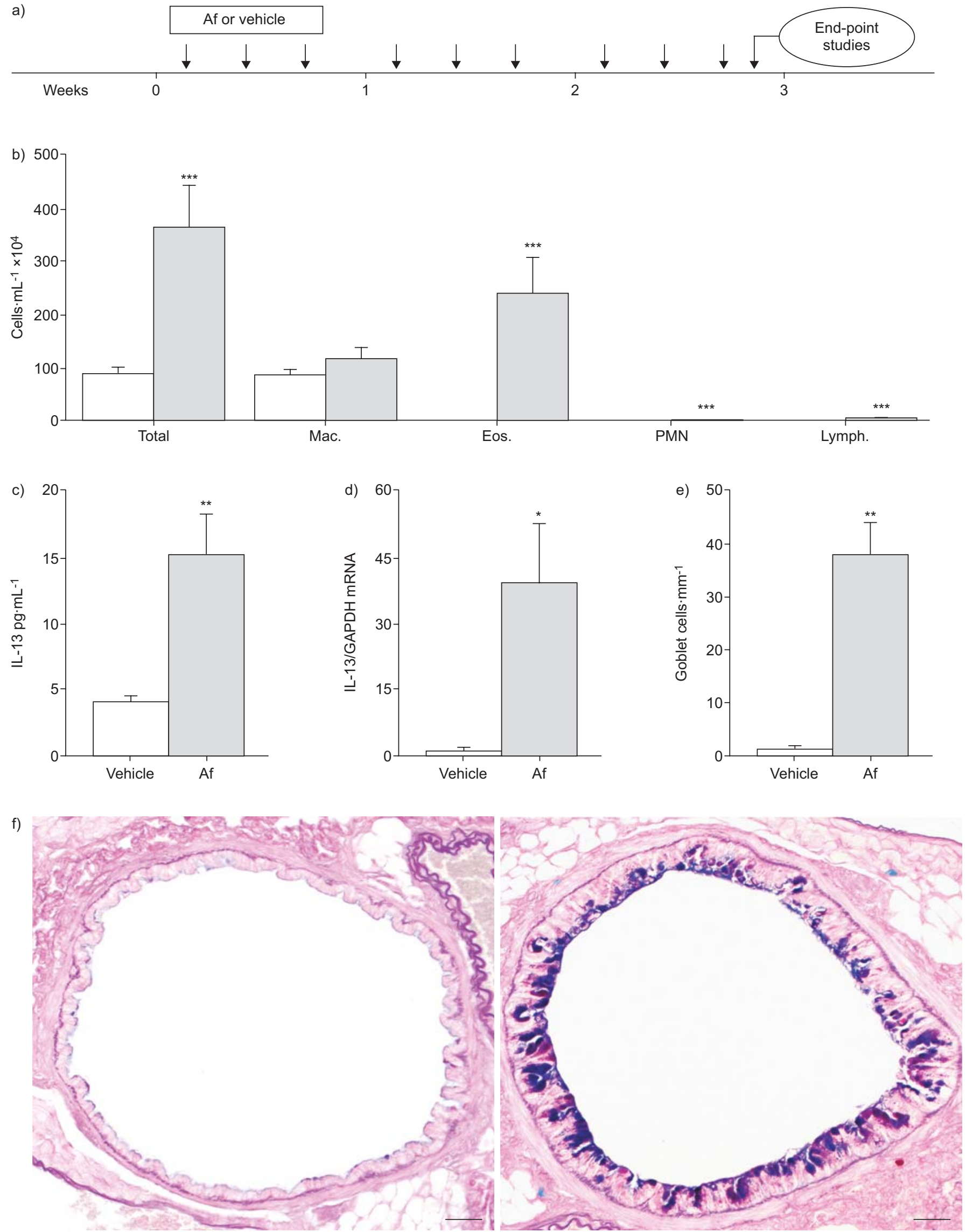
FIGURE 1. Allergic airway inflammation induced by sensitisation with Aspergillus fumigatus extract (Af) in mice. a) Protocol for intratracheal sensitisation with Af, b) effect on total and differential cell counts, C) interleukin (IL)-13 concentration in bronchoalveolar lavage, d) IL-13 transcript levels in lungs, e) airway goblet cell counts and f) airway histology in mice (representative airway sections stained with alcian blue-periodic acid Schiff from Af-sensitised and vehicle-treated mice; scale bars $=100 \mu \mathrm{m}$ ) sensitised with Af or vehicle alone for a period of 3 weeks. Data are presented mean \pm SEM ( $n=5-8$ mice per group). $\square$ : vehicle; $\square$ : Af. Mac.: macrophages; Eos.: eosinophils; Lymph.: lymphocytes; GAPDH: glyceraldehyde 3-phosphate dehydrogenase. *: $p<0.05$ compared with vehicle-treated mice; **: $p<0.01$ compared with vehicle-treated mice; *** $p<0.001$ compared with vehicle-treated mice.

coupled fluid [10], whereas $\mathrm{Cl}^{-}$secretion is mediated by the cystic fibrosis transmembrane conductance regulator (CFTR) [11] and a $\mathrm{Ca}^{2+}$-activated $\mathrm{Cl}^{-}$channel $(\mathrm{CaCC})$, which was recently identified as transmembrane protein (TMEM)16a [12, 13]. Both IL-4 and IL-13 inhibited ENaC-mediated $\mathrm{Na}^{+}$ absorption, and increased CFTR- and CaCC-mediated $\mathrm{Cl}^{-}$ secretion, thereby producing a pro-secretory ion transport phenotype in cultured human bronchial epithelial cells $[8,9]$. These studies suggested that selected Th2 cytokines may be involved in the regulation of ASL volume to improve mucus hydration and promote MCC in allergic airway disease. However, the role of Th2-driven inflammation in regulation of airway ion transport in the complex in vivo pathogenesis of allergic airway inflammation remains unknown.

In the present study, we induced allergic inflammation in mice by repeated mucosal exposure with a natural aeroallergen, Aspergillus fumigatus extract (Af) [14], and studied the effects on ion transport properties and transcript expression of $\mathrm{ENaC}$ subunits $(\alpha, \beta$ and $\gamma)$, CFTR and the CaCC candidate TMEM16a in freshly excised airway tissues. We compared bioelectric properties in native tracheal and bronchial epithelia from Afsensitised and vehicle-treated mice to elucidate effects of allergic inflammation in different airway regions along the tracheobronchial tree. Furthermore, we compared the effect of Afinduced inflammation on bioelectric properties in wild-type (WT) and Stat $6^{-/-}$mice, and studied direct effects of IL-13, in an attempt to obtain mechanistic insights into the link between Th2-driven inflammation and regulation of airway ion transport. These studies show for the first time that allergen-induced airway inflammation induces a pro-secretory ion transport phenotype in vivo, yielding novel insights into the interplay between Th2-driven inflammation and epithelial function in the complex pathogenesis of allergic airway disease, which may lead to new therapeutic strategies for asthma and other airway diseases associated with impaired mucus clearance.

\section{MATERIALS AND METHODS Experimental animals}

All animal studies were approved by the Regierungspräsidium, Karlsruhe, Germany. Female BALB/c WT mice were obtained from Charles River Laboratories (Sulzfeld, Germany). Stat $6^{-/-}$ mice in the BALB/c background [15] were obtained from the Jackson Laboratory (Bar Harbor, ME, USA). Experimental animals were bred by intercrossing of Stat $6^{+/-}$mice; offspring were genotyped by PCR of genomic DNA, as previously described [15], and 6-8-week-old Stat6 $6^{-1-}$ mice and WT litter mates were used for all experiments. Mice were housed in a specific pathogen-free animal facility and had free access to food and water.

\section{Allergen exposure}

Allergic airway inflammation was induced by repeated airway sensitisation with Af (Hollister-Stier Laboratories, Spokane,
WA, USA) according to previously established protocols [14]. In brief, mice were anaesthetised by inhalation of isoflurane ( $3 \%$ in oxygen) and $20 \mu \mathrm{L}$ of either $\mathrm{Af}\left(2 \mathrm{mg} \cdot \mathrm{mL}^{-1}\right)$ dissolved in $0.9 \% \mathrm{NaCl}$ or $0.9 \% \mathrm{NaCl}$ alone, were instilled intratracheally three times per week, for a period of 3 weeks. All end-point studies were performed $24 \mathrm{~h}$ after the last allergen exposure (fig. 1a).

\section{IL-13 instillation}

IL-13 was administered by repeated intratracheal instillation as previously described [16]. In brief, $5 \mu \mathrm{g}$ recombinant murine IL-13 (Peprotech, Hamburg, Germany) dissolved in $50 \mu \mathrm{L}$ phosphate-buffered saline (PBS) containing $0.1 \%$ bovine serum albumin (low-endotoxin; Sigma, Steinheim, Germany) or an equal volume of vehicle alone, were administered by intratracheal instillation once daily for three consecutive days. Endpoint studies were performed $24 \mathrm{~h}$ after the last IL-13 instillation.

\section{Bronchoalveolar lavage cell counts and IL-13 measurements}

Mice were deeply anesthetised via intraperitoneal injection of a combination of ketamine and xylazine $\left(120\right.$ and $16 \mathrm{mg} \cdot \mathrm{kg}^{-1}$ respectively) and killed by exsanguination, by cutting the renal arteries. A median sternotomy was performed, the trachea was cannulated, the left mainstem bronchus was ligated and the right lung was lavaged with PBS as previously described [17]. Bronchoalveolar lavage (BAL) samples were centrifuged and the cell-free supernatant was stored at $-80^{\circ} \mathrm{C}$. Total cell counts were determined using a haemocytometer and differential cell counts were determined in cytospin preparations stained with May-Grünwald-Giemsa [17]. IL-13 concentration in BAL supernatant was measured by ELISA (R\&D Systems, Minneapolis, MN, USA) according to the manufacturer's instructions [17].

\section{Histology and airway morphometry}

Left lungs were removed through the median sternotomy, immersion-fixed in 10\% neutral-buffered formalin and embedded in paraffin. Lungs were sectioned transversally at the level of the proximal intrapulmonary main axial airway. 5$\mu \mathrm{m}$ sections were cut and stained with alcian blue-periodic acid Schiff (AB-PAS) as previously described [17]. Images were captured with an Olympus IX-71 microscope interfaced with a SIS Colorview I Camera Set (Olympus, Hamburg, Germany) using the $10 \times$ objective. Goblet cells were identified by the presence of intracellular AB-PAS-positive material and numeric cell densities were determined per $\mathrm{mm}$ of the basement membrane using an interactive image measurement tool (celîF image analysis software; Olympus, Hamburg, Germany), as previously described [17].

\section{Electrogenic ion transport measurements}

Anaesthetised mice were killed by exsanguination and airway tissues were dissected using a stereomicroscope as previously 
described [18]. In brief, the trachea and mainstem bronchi were exposed by a median incision of the anterior part of the neck and a sternotomy. Airway tissues were freed from surrounding muscle, vessels and connective tissue by blunt dissection in situ. Next, tracheae or mainstem bronchi were excised, the anterior part with the cartilage rings was cut open longitudinally, the pars membranacea was exposed and tissues were immediately mounted into perfused micro-Ussing chambers with circular open areas of $0.8 \mathrm{~mm}^{2}$ for tracheal tissues and $0.5 \mathrm{~mm}^{2}$ for bronchial tissues [19]. The luminal and basolateral bath was perfused continuously at a rate of $10 \mathrm{~mL} \cdot \mathrm{min}^{-1}$, with a solution of the following composition: $145 \mathrm{mM} \mathrm{NaCl}, 0.4 \mathrm{mM} \mathrm{KH} \mathrm{PO}_{4}, 1.6 \mathrm{mM} \mathrm{K}_{2} \mathrm{HPO}_{4}, 5 \mathrm{mM}$ Dglucose, $1 \mathrm{mM} \mathrm{MgCl}_{2}, 1.3 \mathrm{mM}$ calcium gluconate. The $\mathrm{pH}$ was adjusted to 7.4. Experiments were performed at $37^{\circ} \mathrm{C}$ under open-circuit conditions as previously described [19]. In brief, values for the transepithelial voltage $(V$ te) were referenced to the serosal side. The transepithelial resistance (Rte) was determined by applying intermittent ( $1 \mathrm{~s})$ current pulses $(\Delta I=0.5 \mu \mathrm{A})$ and the equivalent short-circuit current (Isc) was calculated according to Ohm's law from $V$ te and Rte (Isc $=V$ te $/$ $R$ te). After an equilibration period of $40 \mathrm{~min}$ in the Ussing chamber, basal Isc was determined and amiloride $(100 \mu \mathrm{M}$, luminal) was added to inhibit electrogenic ENaC-mediated $\mathrm{Na}^{+}$absorption. Then, 3-isobutyl-1-methylxanthine (IBMX; $100 \mu \mathrm{M}$, luminal $)$ and forskolin $(1 \mu \mathrm{M}$, luminal), and uridine 5 '-triphosphate (UTP) $(100 \mu \mathrm{M}$, luminal) were added sequentially to induce cyclic adenosine 5'-monophosphate (cAMP)mediated and $\mathrm{Ca}^{2+}$-activated $\mathrm{Cl}^{-}$secretion, respectively [10]. Additionally, we performed experiments in which bumetanide $\left(100 \mu \mathrm{M}\right.$, basolateral), an inhibitor of the basolateral $\mathrm{Na}^{+}-\mathrm{K}^{+}-$ $2 \mathrm{Cl}^{-}$cotransporter, was added under basal conditions or in the presence of amiloride to block transepithelial $\mathrm{Cl}^{-}$secretion [20]. Amiloride, IBMX, forskolin and bumetanide were obtained from Sigma (Steinheim, Germany) and UTP was obtained from GE Healthcare (Hatfield, UK). All chemicals were of the highest grade of purity available.

\section{Real-time RT-PCR}

Right lungs and tracheae were immediately stored in RNAlater ${ }^{\circledR}$ (Applied Biosystems, Darmstadt, Germany). RNA was isolated using Trizol reagent (Invitrogen, Karlsruhe, Germany). For transcript expression studies in tracheal tissues, tracheae from three mice of the same genotype and treatment group were pooled. RNA purity and quantity were determined using a NanoDrop ND100 spectrophotometer (PeqLab, Erlangen, Germany) and integrity was verified by agarose gel electrophoresis. cDNA was obtained by reverse transcription of $1 \mu \mathrm{g}$ of total RNA (Superscript III RT; Invitrogen, Karlsruhe, Germany). Quantitative real-time RT-PCR for $\alpha \mathrm{ENaC}, \beta E N a C$, $\gamma$ ENaC, CFTR, TMEM16a, IL-13 and glyceraldehyde 3-phosphate dehydrogenase (GAPDH) was performed on an Applied Biosystems 7500 Real Time PCR System using TaqMan universal PCR master mix and inventoried TaqMan gene expression assays according to the manufacturer's instructions (Applied Biosystems, Darmstadt, Germany). Relative fold changes in target gene expression were determined from the efficiency of the PCR reaction and the crossing point deviation between Af-sensitised and vehicle-treated mice, and normalised to the expression of the reference gene GAPDH, as previously described [17].

\section{Statistics}

All experiments were performed by an investigator blinded to the treatment group and the genotype of the mice. Data were analysed with SigmaStat version 3.1 (Systat Software, Erkrath, Germany) and are presented as mean \pm SEM. We performed statistical analyses using unpaired t-test, Mann-Whitney Rank Sum test, one-way ANOVA and Kruskal-Wallis ANOVA on ranks as appropriate, and $\mathrm{p}<0.05$ was the cut-off to indicate statistical significance.

\section{RESULTS}

\section{Induction of allergic airway inflammation by intratracheal sensitisation with Af in mice}

Previous studies have demonstrated that IL-4 and IL-13 act as potent modulators of epithelial ion transport in vitro [8, 9]; however, the role of this regulatory function in the complex in vivo pathogenesis of allergic airway inflammation has not been studied. To elucidate the effect of allergic inflammation on airway ion transport in vivo, we sensitised mice with a natural aeroallergen, $A$. fumigatus, by repeated intratracheal instillation for a period of 3 weeks (fig. 1a). Similarly to previous studies [14], this sensitisation protocol produced a robust allergic inflammation characterised by airway eosinophilia (fig. 1b), increased levels of the Th2 cytokine IL-13 in BAL fluid (fig. 1c), increased IL-13 transcript levels in lung tissues (fig. 1d), airway goblet cell metaplasia and mucus hypersecretion (figs 1e and f) in Af-sensitised compared with vehicle-treated mice.

\section{Effects of allergic inflammation on epithelial ion transport in the trachea}

To determine the role of allergen-induced inflammation in regulation of airway ion transport in vivo, we first studied its effects on tracheal epithelia, a tissue commonly used for studies of airway ion transport in mice [10, 13, 18]. Freshly excised tracheal tissues were mounted in perfused micro-Ussing chambers and basal bioelectric properties, amiloride-sensitive $\mathrm{Na}^{+}$absorption, and cAMP-mediated and UTP-induced $\mathrm{Cl}^{-}$ secretion were compared in Af-sensitised and vehicle-treated mice. Isc under basal conditions, as well as amiloride-sensitive Isc, was not different in tracheal tissues from Af-sensitised compared with vehicle-treated mice (figs $2 a-d$ ). The amilorideinsensitive residual Isc in the presence of amiloride block was significantly increased by allergic airway inflammation (fig. 2e), whereas the cAMP-induced (IBMX and forskolin) and $\mathrm{Ca}^{2+}$ activated (UTP) $\mathrm{Cl}^{-}$secretory responses were not different in tracheal tissues from Af-sensitised compared with vehicletreated mice (figs $2 \mathrm{f}$ and $\mathrm{g}$ ). Taken together, these results demonstrate that allergic inflammation caused an increase in amiloride-insensitive Isc in native tracheal tissues. However, our in vivo model of allergic airway inflammation did not produce modulation of ENaC-mediated $\mathrm{Na}^{+}$absorption or agonistinduced $\mathrm{Cl}^{-}$secretion in native tracheal tissues.

Next, we determined the effect of Af-induced airway inflammation on mRNA transcript levels of these ion channels in tracheal tissues by quantitative real-time RT-PCR. Consistent with the results obtained from ion transport measurements (fig. 2), expression levels of $\alpha \mathrm{ENaC}, \beta \mathrm{ENaC}, \gamma \mathrm{ENaC}$ and TMEM16a did not differ in tracheal tissues from Af-sensitised compared with vehicle-treated mice (fig. 3). In agreement with previous functional studies that demonstrated that CFTR is 


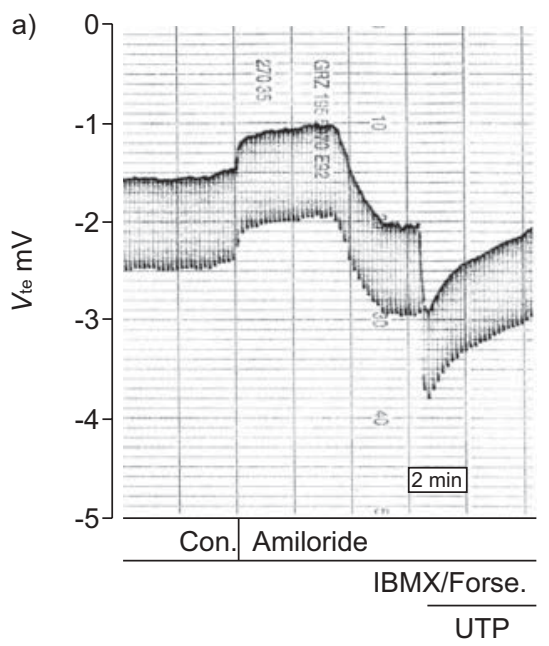

b)
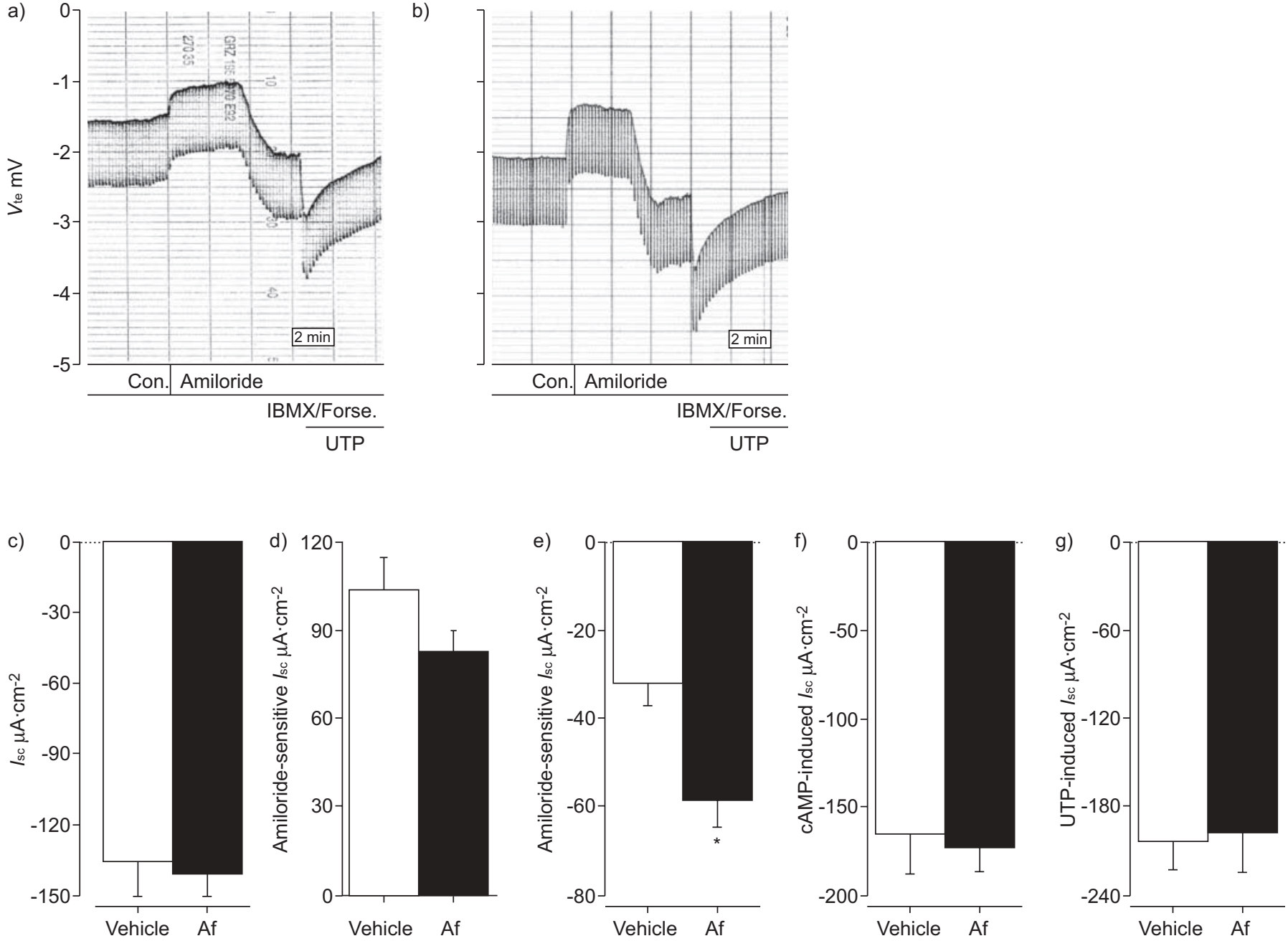

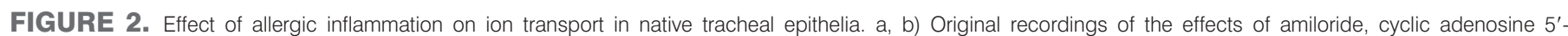

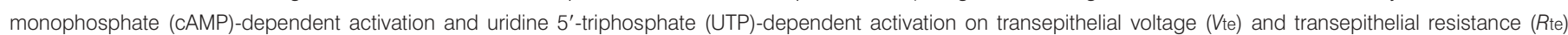

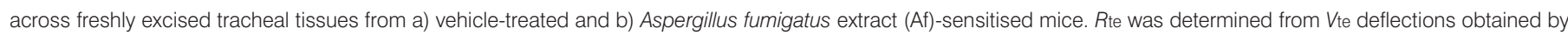

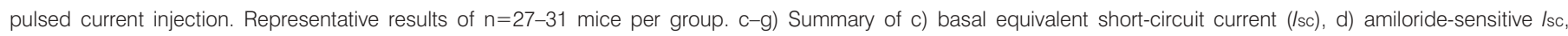

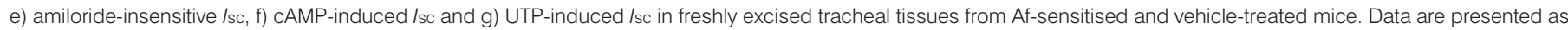
mean \pm SEM ( $n=27-31$ mice per group). Con.: control; IBMX: 3-isobutyl-1-methylxanthine; Forse.: forskolin. *: $p<0.001$ compared with vehicle-treated mice.

expressed at very low levels in mouse trachea [18], signals for CFTR transcripts were below the detection limit in tracheal tissues from both groups (data not shown).

\section{Allergic inflammation induces a pro-secretory ion transport phenotype in bronchi}

In an attempt to explain the differences in ion transport modulation by Th2 cytokines in our studies in native tracheal tissues (figs 2 and 3 ) and previous in vitro studies in cultured human bronchial epithelial cells [8,9], we hypothesised that these differences may be caused by regional differences in ion transport properties and/or regulation along the tracheobronchial tree. To test this hypothesis, we extended our studies in the Af model of allergic airway inflammation to freshly excised bronchial tissues.

First, we compared the bioelectric properties in freshly excised bronchial and tracheal tissues from vehicle-treated
WT mice to determine regional differences in the absence of allergic inflammation. As shown in table 1, several distinct ion transport properties were detected in bronchial versus tracheal epithelia. Under baseline conditions, Rte was not different in the two airway regions, whereas $V$ te and Isc were lower in bronchial compared to tracheal tissues (table 1). Overall, the absolute values for amiloride-sensitive Isc $(p<0.001)$, residual amiloride-insensitive Isc $(p<0.001)$, cAMP-induced Isc $(\mathrm{p}<0.01)$ and UTP-induced Isc $(\mathrm{p}<0.001)$ were significantly lower in bronchial compared to tracheal tissues (table 1). However, when the different Isc responses were expressed as a fraction of the basal Isc in each tissue, it became apparent that the fractional amiloride-sensitive Isc $(p<0.01)$ as well as the fold-increase in Isc upon cAMPdependent activation $(p<0.001)$ were significantly higher, whereas the fractional amiloride-insensitive $I_{s c}(p<0.01)$, as well as the fold-increase in Isc in response to UTP-induced activation $(p<0.05)$, were significantly lower in bronchial 

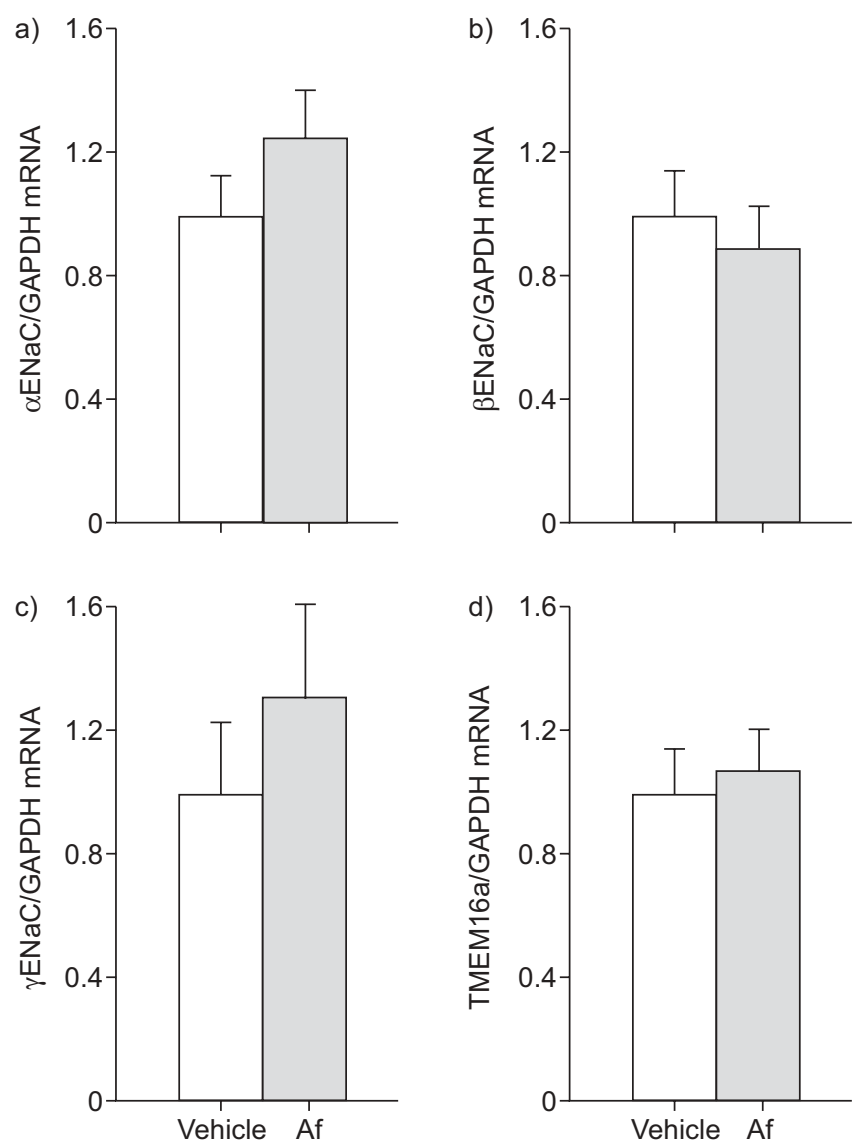

FIGURE 3. Effect of allergic inflammation on expression of epithelial $\mathrm{Na}^{+}$ channel (ENaC) subunits and transmembrane protein (TMEM)16a in native tracheal epithelia. a-d) Transcript levels of a) $\alpha E N a C, b) \beta E N a C, c) \gamma E N a C$ and d) TMEM16a in freshly excised tracheal tissues from Aspergillus fumigatus extract (Af)-sensitised and vehicle-treated mice. Data are expressed as fold changes over vehicle-treated mice. Data are presented as mean \pm SEM. $n=5$ mice per group.

versus tracheal tissues. These results indicate that, in comparison to trachea, 1) bronchial tissues are more absorptive under normal conditions, 2) the relative capacity to induce $\mathrm{Cl}^{-}$ secretion is greater in bronchi and 3) $\mathrm{Cl}^{-}$secretory responses are, to a greater extent, elicited by cAMP agonists and, to a lesser extent, by $\mathrm{Ca}^{2+}$-dependent activation in native bronchial versus tracheal epithelia.

Next, we determined the effect of allergic inflammation on ion transport in bronchi by comparing bioelectric properties of freshly excised bronchial tissues from Af-sensitised and vehicle-treated mice. Similar to trachea, the basal Isc was not altered by allergen-induced inflammation (fig. 4e). In contrast to tracheal tissues, amiloride-sensitive Isc was significantly inhibited $(p<0.05)$ in freshly excised bronchi from Af-sensitised compared with vehicle-treated mice (fig. 4f). As observed in tracheal tissues, the amiloride-insensitive residual Isc was significantly increased $(\mathrm{p}<0.01)$ in bronchi from Af-sensitised mice (fig. 4g). The cAMP-mediated $\mathrm{Cl}^{-}$secretion in bronchial tissues was attenuated by allergic inflammation (fig. 4h), whereas the UTP-induced $\mathrm{Cl}^{-}$secretory response was significantly $(p<0.05)$ increased in native bronchial tissues from Af-sensitised mice compared to vehicle-treated controls (fig. 4i). Taken together, these results demonstrate that inhibition of ENaC-mediated $\mathrm{Na}^{+}$absorption and upregulation of $\mathrm{Ca}^{2+}$-activated $\mathrm{Cl}^{-}$secretion by allergic inflammation produced a pro-secretory ion transport phenotype in bronchi (fig. 4).

\section{Th2-mediated modulation of ENaC-mediated $\mathrm{Na}^{+}$ absorption and $\mathrm{Ca}^{2+}$-activated $\mathrm{Cl}^{-}$secretion in bronchi is Stat6-dependent}

Previous studies demonstrated that Stat 6 plays a central role in the regulation of Th2-mediated allergic airway inflammation in asthma, including airway eosinophilia, mucus hypersecretion and airway hyperresponsiveness [7, 15], but the role of Stat6 signalling in regulation of epithelial ion transport has not been studied. In an attempt to elucidate the mechanisms underlying regulation of airway ion transport by allergic inflammation, we compared responses to Af sensitisation in bronchial tissues from WT and Stat $6^{-/-}$mice. As shown in figure 4, Stat6 knockout had no effect on basal Isc in the absence or presence of Af-induced inflammation (fig. 4e). However, the inhibition of amiloride-sensitive $\mathrm{Na}^{+}$absorption that was caused by allergic inflammation in bronchi from WT mice was completely abrogated in Stat $6^{-/-}$mice (fig. 4f). While the Af-induced upregulation of amiloride-insensitive Isc

TABLE 1 Bioelectric properties of freshly excised native tracheal and bronchial tissues

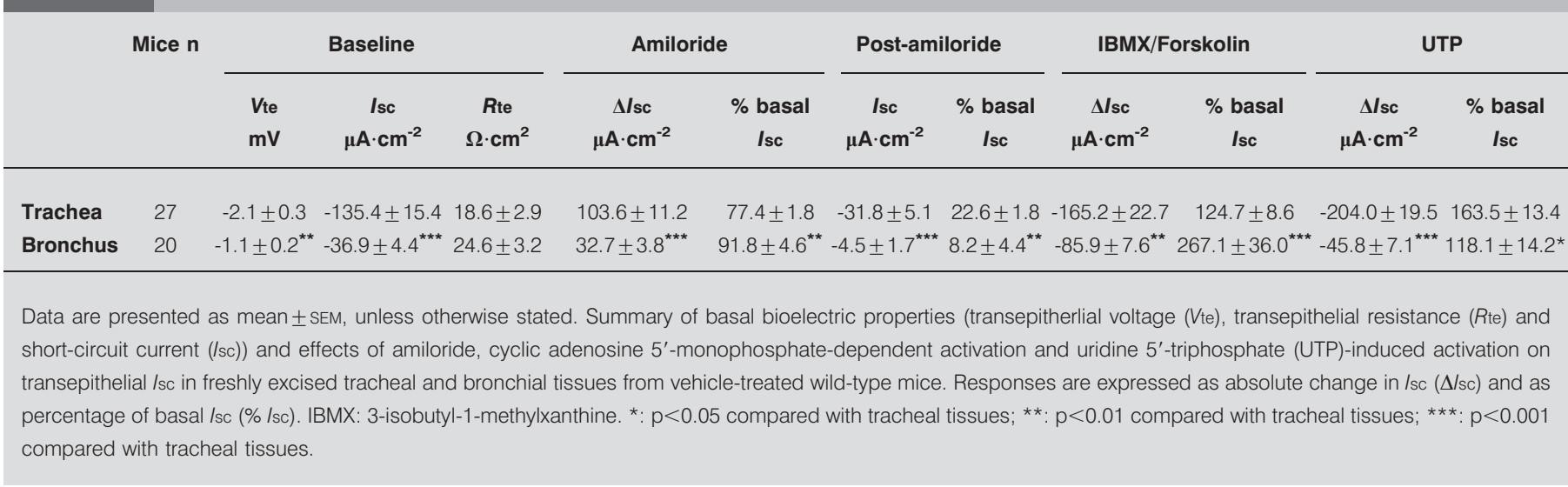




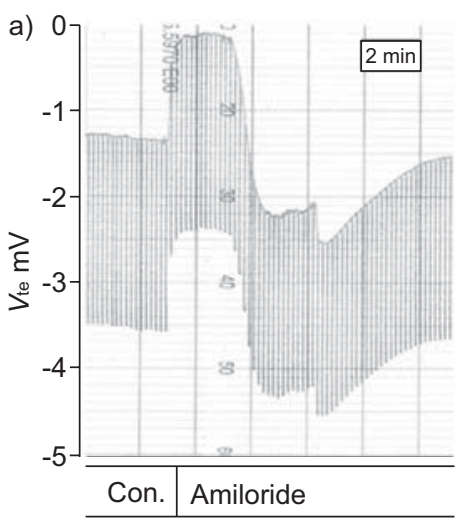

IBMX/Forse.

UTP

e)

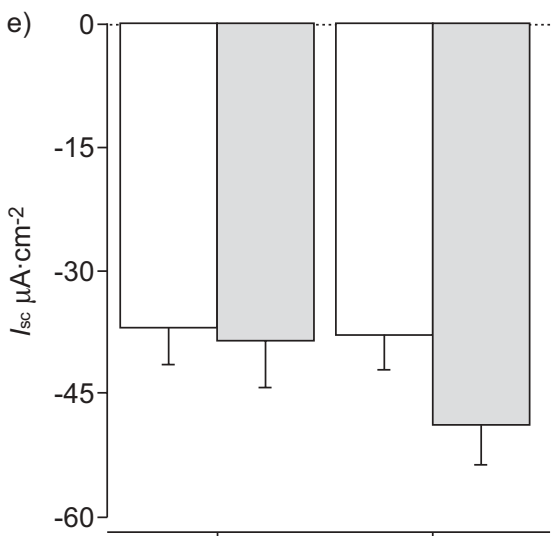

b)

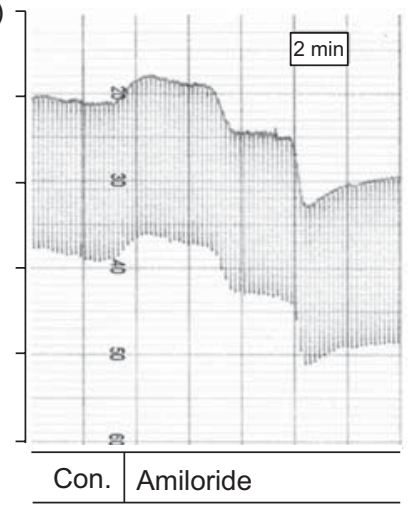

IBMX/Forse. c)

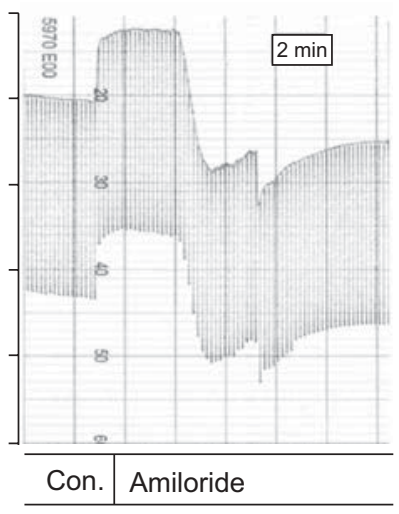

IBMX/Forse. d)

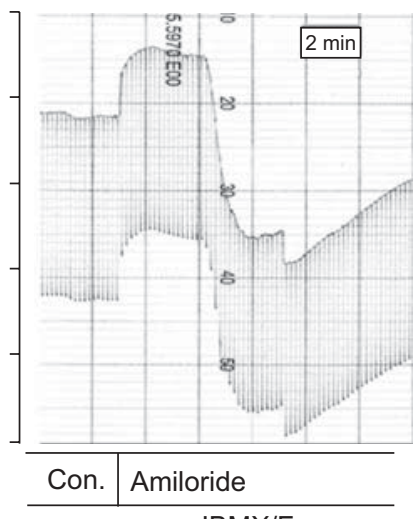

IBMX/Forse.

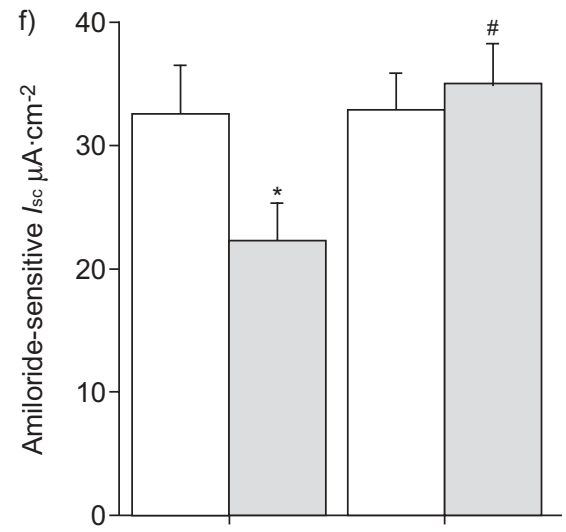

i)

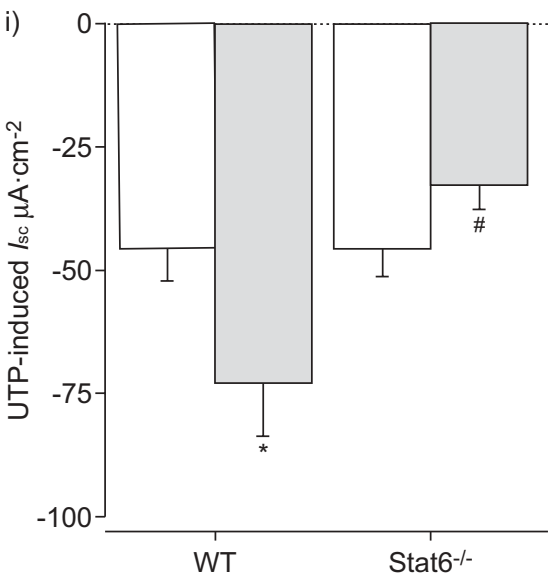

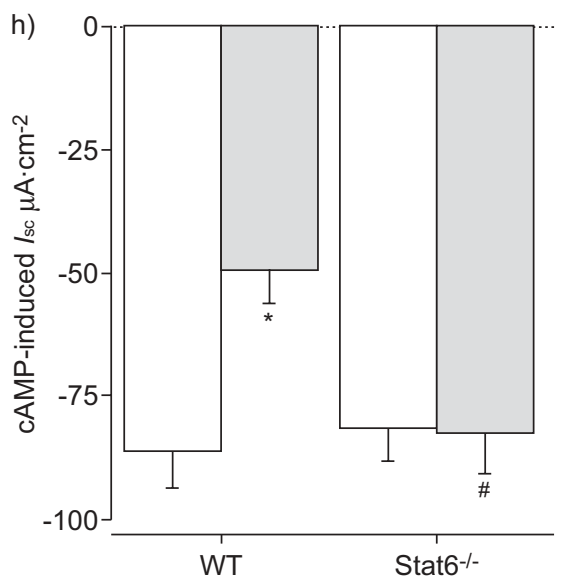

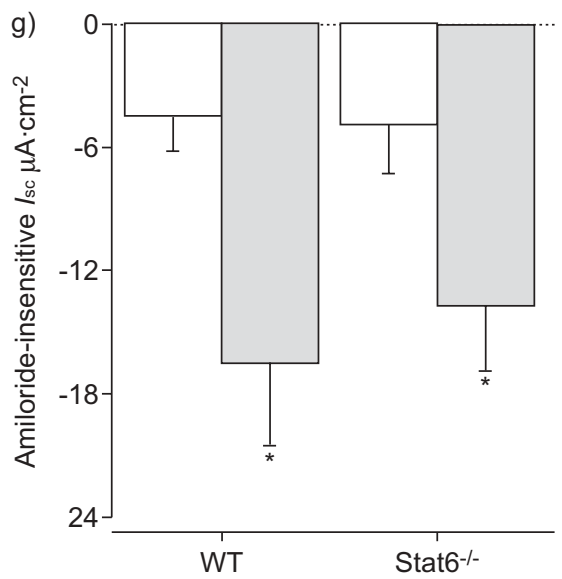

FIGURE 4. Allergic inflammation modulates ion transport in native bronchial epithelia in a signal transducer and activator of transcription (Stat)6-dependent manner. a-d) Original recordings of the effects of amiloride, cyclic adenosine $5^{\prime}$-monophosphate (cAMP)-dependent activation and uridine $5^{\prime}$-triphosphate (UTP)-dependent activation on transepithelial voltage ( $\mathrm{Vte}$ ) and transepithelial resistance across freshly excised bronchial tissues from a, c) vehicle-treated and b, d) Aspergillus fumigatus (Af) sensitised wildtype (WT) mice (a, b) and Stat6 ${ }^{-/}$littermates (c, d). Summary of e) basal equivalent short-circuit current (Isc), f) amiloride-sensitive /sc, g) amiloride-insensitive /sc, h) cAMPinduced /sc and i) UTP-induced /sc in freshly excised bronchial tissues from Af-sensitised $(\square)$ and vehicle-treated $(\square)$ WT mice and Stat6 ${ }^{-/}$littermates. Data are presented as mean \pm SEM ( $n=18-25$ mice per group). Con.: control; IBMX: 3-isobutyl-1-methylxanthine; Forse.: forskotin. *: $p<0.05$ compared with vehicle-treated mice of the same genotype; ${ }^{*}: p<0.005$ compared with Af-sensitised WT mice.

observed in WT mice was not affected in Stat $6^{-/-}$littermates (fig. $4 \mathrm{~g}$ ), both the reduction in the cAMP response, as well as the upregulation of UTP-induced $\mathrm{Cl}^{-}$secretion observed in bronchial tissues from Af-sensitised WT mice was completely abolished in Stat $^{-/-}$mice (figs $4 \mathrm{~h}$ and i). These results demonstrate that Stat6 signalling is directly involved in regulation of epithelial ion transport in allergic airway disease. 


\section{Stat6 reduces expression of $\alpha, \beta$ and $\gamma E N a C$ in allergic airway inflammation}

Because many effects of Stat 6 are mediated through regulation of target gene expression [7, 15, 21], we next sought to determine if Stat6-dependent regulation of ion transport by allergic inflammation was associated with changes in transcript levels of ENaC, CFTR and the CaCC candidate TMEM16a in lungs from Af-sensitised mice. These studies were performed in lung tissues, because the yield of mRNA from bronchial tissues was too low for reliable quantification of these genes by real-time RT-PCR. Consistent with the results from ion transport measurements in bronchial tissues (fig. 4f), allergic inflammation caused a significant reduction in expression levels of $\alpha \mathrm{ENaC}(\mathrm{p}<0.01), \quad \beta \mathrm{ENaC} \quad(\mathrm{p}<0.01)$ and $\gamma \mathrm{ENaC} \quad(\mathrm{p}<0.05)$ subunits in lungs from WT mice (fig. $5 a-c)$. This effect was entirely abolished in Af-sensitised Stat $6^{-/-}$mice (fig. 5a-c). CFTR and TMEM16a expression remained unchanged in lungs from Af-sensitised, compared with vehicle-treated, WT mice and transcript levels were not altered in Stat $6^{-/-}$mice in the absence or presence of allergic inflammation (figs $5 \mathrm{~d}$ and e). These results indicate that Stat6-dependent regulation of $\mathrm{ENaC}$ function in allergic airway inflammation was mediated by transcriptional regulation of ENaC genes, whereas Stat6-dependent regulation of cAMP-mediated and UTP-induced $\mathrm{Cl}^{-}$secretion was independent of transcriptional regulation of CFTR or TMEM16a.

\section{IL-13 mimics effects of allergen-induced inflammation on airway ion transport}

To determine more directly the role of Th2 cytokines in modulation of airway ion transport, we treated WT mice by intratracheal instillation of IL-13 and studied the effects on bioelectric properties in freshly excised airway tissues. In bronchi, similar to Af-induced allergic inflammation, IL-13 had no effect on Isc under basal conditions; however, the amiloridesensitive Isc was significantly reduced $(p<0.001)$ and the residual $I_{\mathrm{sc}}$ in the presence of amiloride was significantly increased $(p<0.01)$ in IL-13 treated compared with vehicletreated mice (fig. $6 \mathrm{a}-\mathrm{c}$ ). Furthermore, effects of IL-13 on the cAMP-induced Isc and UTP-dependent Isc (figs 6d and e) were also similar to Af-sensitisation (fig. 4). In the trachea, IL-13 produced a significant increase in amiloride-insensitive Isc $(p<0.05)$, as observed in the Af model (data not shown). These results suggest that the Th2 cytokine IL-13 plays an important role in modulation of epithelial ion transport in the complex in vivo pathogenesis of allergic airway inflammation in mice.
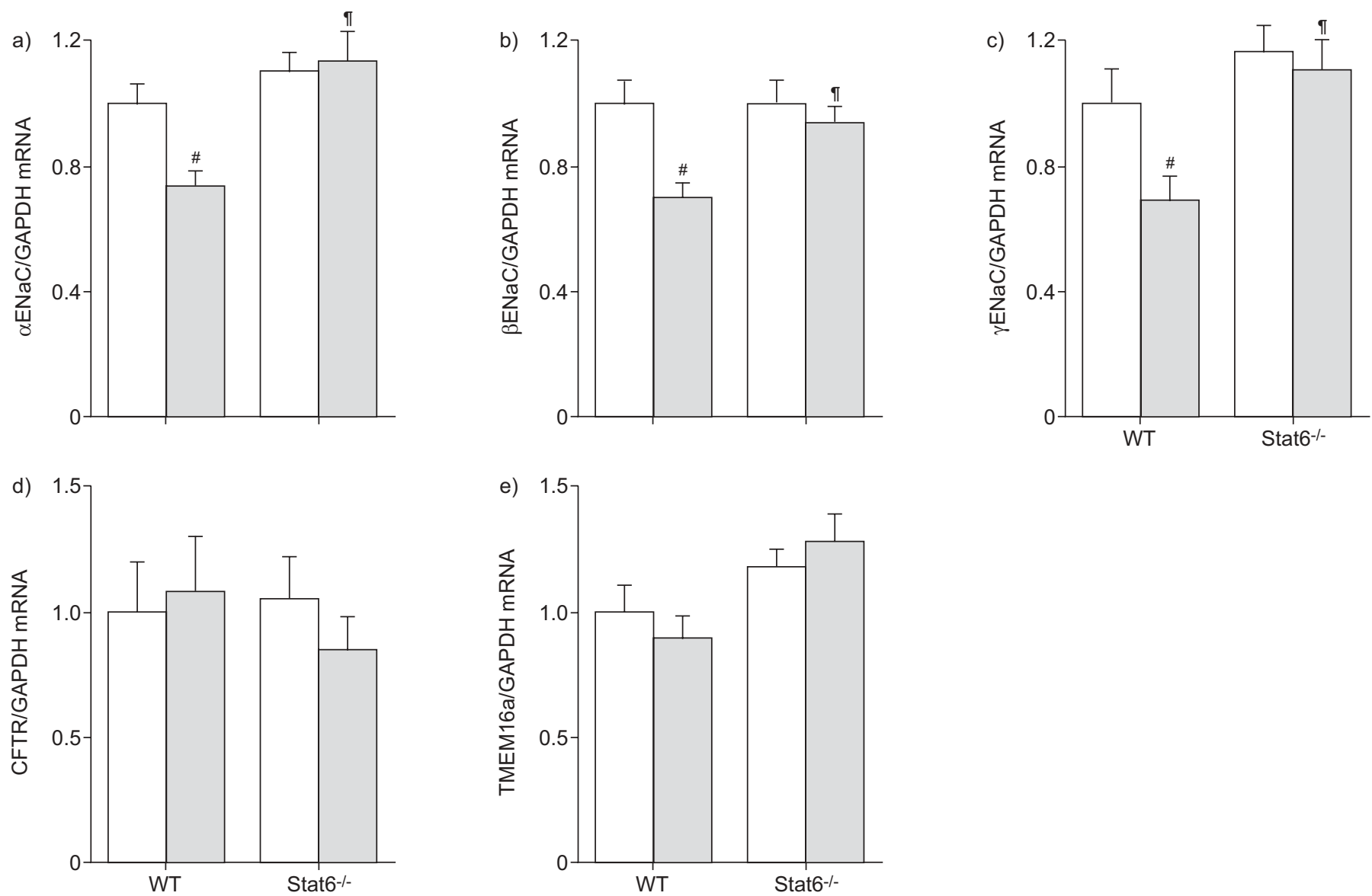

FIGURE 5. Allergic inflammation modulates pulmonary expression of epithelial $\mathrm{Na}^{+}$channel (ENaC) subunits, but not cystic fibrosis transmembrane conductance regulator (CFTR) and transmembrane protein (TMEM)16a, in a signal transducer and activator of transcription (Stat)6-dependent manner. Transcript levels of a) $\alpha$ ENaC b) $\beta E N a C, c) \gamma E N a C, d)$ CFTR and e) TMEM16a in lungs from Aspergillus fumigatus extract (Af)-sensitised ( $\square$ ) and vehicle-treated ( $\square$ ) wild-type (WT) mice and Stat6 ${ }^{-1}$ littermates. Data are presented as mean \pm SEM of fold changes from vehicle-treated WT mice ( $n=5-6$ mice per group). ${ }^{\#}: p<0.05$ compared with vehicle-treated WT mice; ?: $\mathrm{p}<0.05$ compared with Af-sensitised WT mice. 

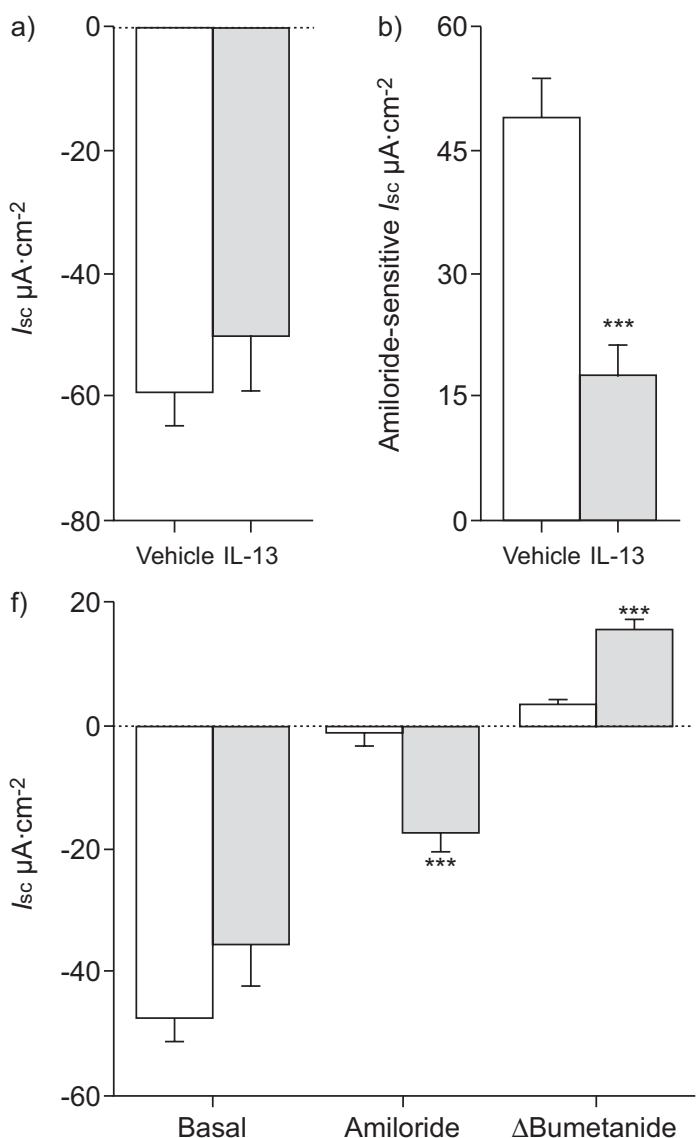
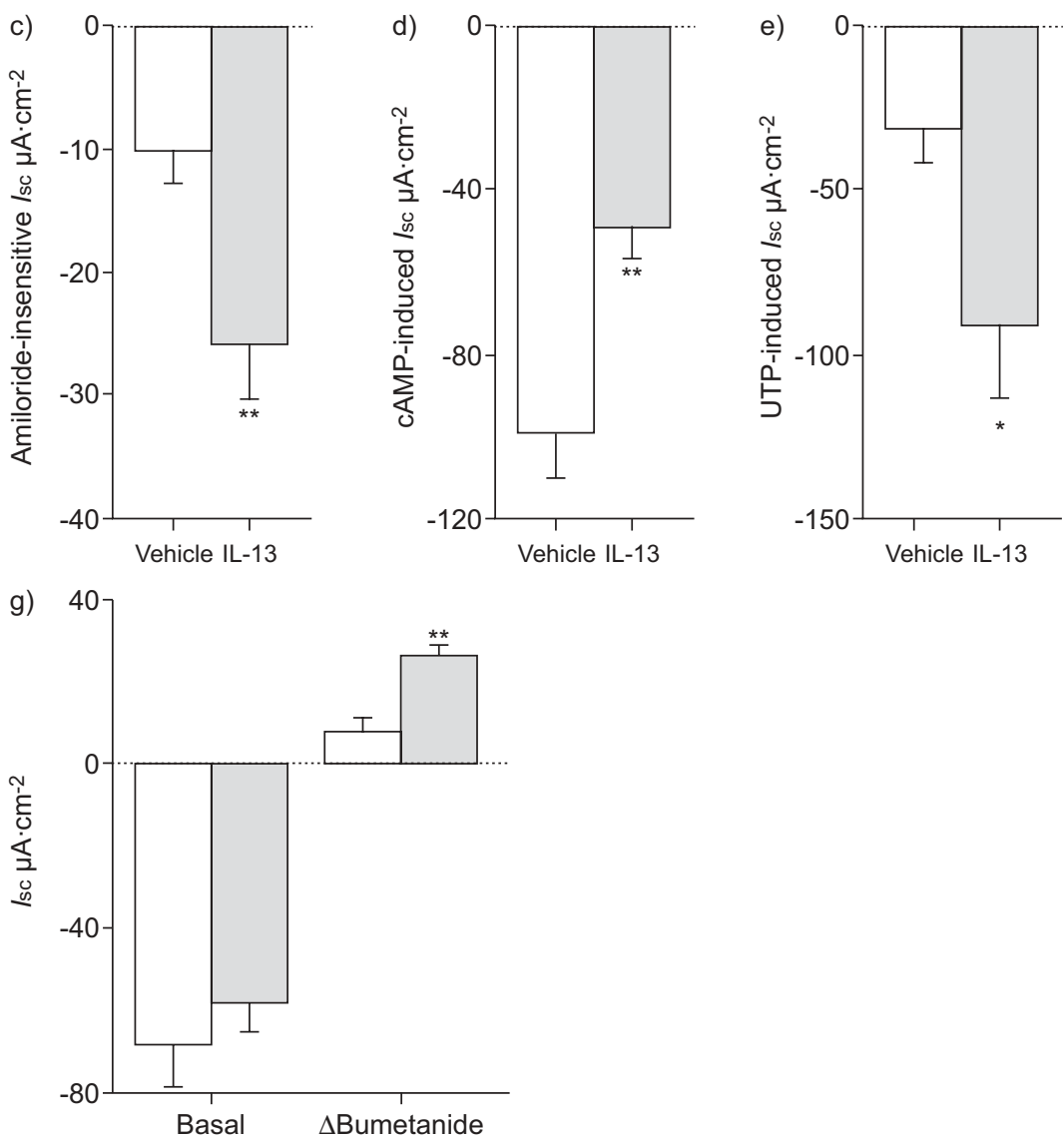

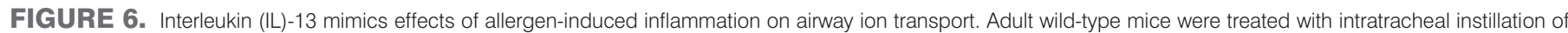

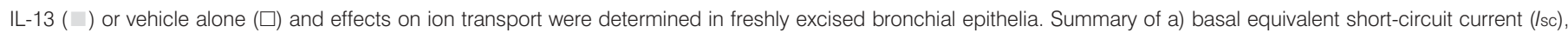

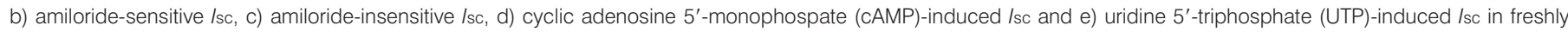

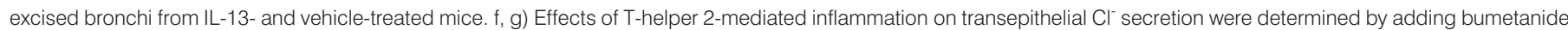

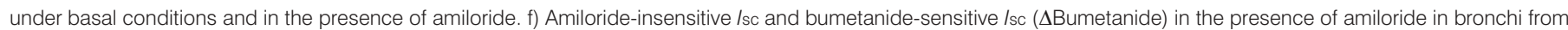

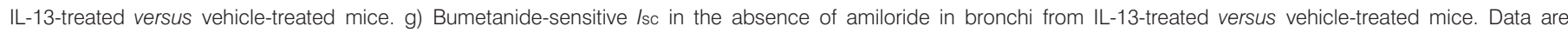

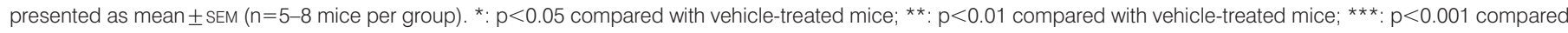
with vehicle-treated mice.

\section{Th2-mediated airway inflammation promotes $\mathrm{Cl}^{-}$secretion}

To determine the origin of the increased amiloride-insensitive Isc observed in Th2-mediated airway inflammation, airway tissues were perfused with bumetanide to block transepithelial $\mathrm{Cl}^{-}$secretion [20]. In the presence of amiloride, the bumetanidesensitive Isc was significantly increased in bronchial $(\mathrm{p}<0.001$; fig. 6f) and tracheal ( $<<0.05$; data not shown) tissues from IL13 treated mice compared with vehicle-treated mice. Because amiloride hyperpolarises the apical membrane voltage and may thus generate a driving force for $\mathrm{Cl}^{-}$secretion that is not present in the absence of ENaC blockade, we next determined the effects of bumetanide under basal conditions. In the absence of amiloride, bumetanide had no effect on basal airway ion transport in vehicle-treated mice, but inhibited basal Isc significantly in bronchi $(\mathrm{p}<0.01$; fig. $6 \mathrm{~g})$ and tracheae $(\mathrm{p}<0.05$; data not shown) from IL-13 treated mice. Notably, the bumetanide-sensitive Isc was in the same range in the absence and presence of amiloride (fig. $6 \mathrm{f}$ and $\mathrm{g}$ ). These results indicate that Th2-mediated inflammation induced basal $\mathrm{Cl}^{-}$secretion, contributing to a pro-secretory ion transport phenotype in allergic airway disease.

\section{DISCUSSION}

The results of the present study 1) demonstrate, for the first time, that Th2-mediated allergic airway inflammation in mice, induced by mucosal sensitisation with Af as natural aeroallergen or by intratracheal instillation of the Th2 cytokine IL-13, produces modulation of airway epithelial ion transport, in addition to eosinophilic inflammation, goblet cell metaplasia and mucus hypersecretion, and 2) identify alterations in airway ion transport as an additional abnormality in the complex in vivo pathogenesis of allergic airway disease.

In the trachea, a tissue commonly used for airway ion transport studies in mice, Af-induced airway inflammation produced a substantial increase in residual Isc in the presence of amiloride block, but had no effects on $\mathrm{ENaC}$-mediated $\mathrm{Na}^{+}$absorption or cAMP-dependent and UTP-induced $\mathrm{Cl}^{-}$secretion (fig. 2). In bronchi, the response to allergic inflammation was more complex (fig. 4). Similar to the trachea, amiloride-insensitive Isc was increased in allergen-sensitised mice. In addition, ENaC-mediated $\mathrm{Na}^{+}$absorption and cAMP-induced $\mathrm{Cl}^{-}$secretion were reduced, whereas $\mathrm{CaCC}$-mediated $\mathrm{Cl}^{-}$secretion was 
increased in bronchi from Af-sensitised mice compared to controls. Intratracheal instillation of IL-13 produced similar changes of airway ion transport, demonstrating that the effects of allergic inflammation were Th2-dependent (fig. 6). Addition of bumetanide, a blocker of the $\mathrm{Na}^{+}-\mathrm{K}^{+}-2 \mathrm{Cl}^{-}$cotransporter that inhibits basolateral $\mathrm{Cl}^{-}$uptake and transepithelial $\mathrm{Cl}^{-}$transport, to amiloride pretreated tissues demonstrated that the increase in amiloride-insensitive $I_{\mathrm{sc}}$ in Th2-mediated inflammation reflected elevated $\mathrm{Cl}^{-}$secretion (fig. 6f) [20]. Similarly, the bumetanide-sensitive Isc was also increased in the absence of amiloride, indicating that Th2-mediated airway inflammation increased $\mathrm{Cl}^{-}$secretion under basal conditions (fig. $6 \mathrm{~g}$ ). The modulation of ion transport induced by allergic inflammation in native bronchial tissues largely resembled the effects previously observed in human bronchial epithelial cells after stimulation with selected Th2 cytokines (IL-4 and IL-13) in vitro $[8,9]$. Taken together, these results demonstrate that airway ion transport is actively regulated during an allergen-driven, Th2-mediated airway immune response in vivo. The net effect of the $\sim 2-3$-fold increase in basal $\mathrm{Cl}^{-}$secretion in both tracheal and bronchial tissues, together with the reciprocal regulation of airway $\mathrm{Na}^{+}$absorption and $\mathrm{CaCC}$-mediated $\mathrm{Cl}^{-}$secretion in bronchi (figs 2, 4 and 6) is a pro-secretory ion transport phenotype that promotes fluid secretion and hydration of airway surfaces in allergic airway inflammation.

Proper regulation of ASL volume by coordinate ENaCmediated $\mathrm{Na}^{+}$absorption and $\mathrm{Cl}^{-}$secretion, mediated by $\mathrm{CFTR}$ and $\mathrm{CaCC}$, plays a critical role in maintaining normal MCC, providing an important defense mechanism of the lung $[3,4]$. Previous studies in patients with loss of function mutations in ENaC or CFTR [19, 22-24], and studies in mice with airway-specific overexpression of $\beta \mathrm{ENaC}(\beta \mathrm{ENaC}-\mathrm{Tg})$ $[10,25]$ demonstrated that alterations in the balance between airway $\mathrm{Na}^{+}$absorption and $\mathrm{Cl}^{-}$secretion have profound consequences on ASL homeostasis and mucociliary function, and showed that a pro-secretory ion transport phenotype accelerates MCC, whereas hyperabsorptive phenotypes cause mucociliary dysfunction and chronic airway disease. In this context, the results from our present studies predict that the induction of a pro-secretory ion transport phenotype by Th2driven inflammation improves mucus clearance in the presence of mucus overproduction in allergic airway disease. This hypothesis is supported by a comparison of the pulmonary phenotypes of the $\beta \mathrm{ENaC}-\mathrm{Tg}$ mouse with mouse models of allergic asthma, as well as recent human studies. First, while airway mucus plugging is an invariant feature of the $\beta \mathrm{ENaC}$ Tg mouse [10,17], mucus plug formation was not observed in lungs from Af-sensitised mice (fig. 1 and data not shown) or in other asthma mouse models [5-7, 15], despite the presence of striking goblet cell metaplasia and mucus hypersecretion. Secondly, a recent human study demonstrated that MCC was significantly increased in patients with mild, stable allergic asthma compared to healthy controls [26]. These data are consistent with the hypothesis that a coordinate increase in fluid and mucin secretion induced by Th2-driven airway inflammation may provide a protective mechanism to promote mucus clearance and prevent airway mucus plugging in allergic airway diseases such as asthma.

Conversely, MCC is impaired in patients with acute asthma $[2,27]$. A recent study demonstrated that excess plasma proteins exudated into the airways of patients with acute asthma inhibit protease-dependent degradation of mucins and suggested that a change in viscoelastic properties may impair airway mucus clearance [28]. Since mucin macromolecules are secreted "dry" onto airway surfaces, where they are hydrated by binding water from the ASL [29], we speculate that exuberant mucin secretion may exceed Th2-driven ion transport compensation and cause relative ASL depletion, which may provide an additional mechanism for reduced MCC in acute asthma. Furthermore, we speculate that a reduced capacity to raise fluid secretion in allergic inflammation, e.g. by genetic and/or functional variants of ENaC, CFTR or other ion channels involved in airway fluid secretion, may be a hitherto unrecognised risk factor in the development of mucociliary dysfunction and severe airway mucus plugging observed in fatal asthma [30].

Our study also provides new mechanistic insights into the modulation of airway ion transport by allergic inflammation. First, by comparing effects of Af-induced airway inflammation on bioelectric properties in bronchi of WT and Stat6 $6^{-/-}$mice, we demonstrate that important components of the pro-secretory phenotype induced by allergic inflammation, i.e. ENaCmediated $\mathrm{Na}^{+}$absorption and CaCC-mediated $\mathrm{Cl}^{-}$secretion, depend on Stat6 signalling (fig. 4), which also plays an important role in other components of allergic airway disease, including eosinophilic inflammation, mucus hypersecretion and airway hyperresponsiveness [7, 15, 21]. Because many Stat6-dependent asthma responses are regulated at the level of target gene expression $[15,21]$ and because previous studies in cultured human bronchial epithelial cells showed that stimulation with the Th2 cytokine IL-4 had effects on expression of ENaC subunits, CFTR and TMEM16a [9, 12], we compared the effects of allergic airway inflammation on transcript expression levels of these ion channels in airways from WT and Stat6 ${ }^{-1}$ mice. These studies demonstrated that inhibition of ENaCmediated $\mathrm{Na}^{+}$absorption in bronchi from Af-sensitised WT mice was associated with a significant reduction in pulmonary transcript levels of all three $\mathrm{ENaC}$ subunits $(\alpha, \beta$ and $\gamma)$ and that this effect was Stat6-dependent (fig. 5). Recent evidence suggests that post-translational regulation, e.g. by proteolytic cleavage of $\mathrm{ENaC}$ by extracellular proteases, plays an important role in controlling $\mathrm{Na}^{+}$absorption from airway surfaces [31]. While we did not address possible effects of allergic inflammation on posttranslational regulation, our studies indicate that Stat6-dependent transcriptional regulation of $\mathrm{ENaC}$ may provide a mechanism that contributes to inhibition of epithelial $\mathrm{Na}^{+}$absorption and switching of the epithelium to a pro-secretory ion transport phenotype in Th2 driven airway inflammation.

In contrast, expression levels of CFTR and TMEM16a were not changed in allergen-sensitized WT and Stat6 $6^{-/-}$mice (fig. 5). Given that TMEM16A was recently identified as a CaCC in human bronchial epithelial cell cultures by global gene expression analysis in a search for genes that are differentially regulated by IL-4 [12] and that the CaCC function of its mouse homologue was confirmed in a recent study in TMEM16a ${ }^{-/-}$ mice [13], it was surprising that the Stat6-dependent upregulation of UTP-induced $\mathrm{Cl}^{-}$secretion in allergen-sensitised mice was not associated with changes in TMEM16a expression in our study (fig. 5). These results suggest that a CaCC 
genetically different from TMEM16a participates in UTPmediated $\mathrm{Cl}^{-}$secretion. We speculate that the lack of upregulation of TMEM16a expression, despite a significant increase in UTP-mediated $\mathrm{Cl}^{-}$secretion induced by allergic airway inflammation in our studies (figs 4 and 5), may reflect species differences between expression patterns of different CaCC candidates in human and mouse airway epithelial cells. Alternatively, regulation of TMEM16a expression may differ under cell culture versus in vivo conditions [12, 13]. Furthermore, we demonstrate that the increase in basal $\mathrm{Cl}^{-}$ secretion constituting an important component of the prosecretory ion transport phenotype induced by allergic inflammation was Stat6-independent and not associated with changes in transcript levels of CFTR or TMEM16a (figs 4 and 5). Therefore, our results indicate that future studies are required to define the relative roles of TMEM16a and other $\mathrm{Cl}^{-}$ channel candidates in the in vivo regulation of the prosecretory ion transport phenotype in allergic airway disease.

A comparison of ion transport properties of bronchi versus tracheae in vehicle-treated WT mice (table 1), as well as the different responses to allergen-induced inflammation (figs 2 and 4), demonstrated profound differences in regulation of airway ion transport in these two regions of the tracheobronchial tree. Interestingly, the concept of regional differences in ion and fluid transport in small versus large airways is supported by a previous study that compared primary human bronchial with bronchiolar epithelial cell cultures [32]. The regional differences in native tracheal versus bronchial epithelium may be related to: 1) differences in expression levels of $\mathrm{ENaC}$ subunits and genes contributing to basal and agonistinduced $\mathrm{Cl}^{-}$secretion; 2) differences in local concentrations of mediators, such as Th2 cytokines (Il-4 and Il-13), extracellular nucleotides and nucleosides (ATP and adenosine), which are released in allergic inflammation and act as potent modulators of airway ion transport [8, 9, 33-35]; or 3) local differences in receptor densities, in particular the common IL-4/IL-13 receptor and/or differences in epithelial Stat6 signalling. We predict that further elucidation of the mechanisms underlying these regional differences in basal and regulated airway ion transport may provide novel insights into local (dys)regulation of MCC in response to noxious stimuli in different airway regions of the lung.

In summary, our study shows that Th2-mediated, allergendriven airway inflammation triggers a pro-secretory ion transport phenotype in vivo and indicates that active modulation of airway ion transport is an important effector function in the complex in vivo pathogenesis of allergic airway disease. Furthermore, we demonstrate that important components of this response are mediated by epithelial Stat6 signalling. Our results indicate that coordinate increase in fluid and mucin secretion in Th2-driven airway inflammation may provide a protective mechanism to promote mucus clearance and prevent airway mucus plugging in the presence of mucus overproduction in allergic airway disease, and suggest that dysregulation of this epithelial response may provide a clue to severe airway mucus plugging in fatal asthma.

\section{SUPPORT STATEMENT}

This study was supported by the Deutsche Forschungsgemeinschaft (DFG MA 2081/3-2 and MA 2081/4-1) and the Ernest-Solvay-Stiftung.
P. Anagnostopoulou received a short-term fellowship from the Graduate Academy of Heidelberg (Heidelberg, Germany).

\section{STATEMENT OF INTEREST}

None declared.

\section{ACKNOWLEDGEMENTS}

We thank Z. Zhou (Division of Paediatric Pulmonology and Auergy and Cystic Fibrosis Center, Dept of Paediatrics III, University of Heidelberg, Heidelberg, Germany) for expert assistance with allergen exposures and for helpful discussions.

\section{REFERENCES}

1 Elias JA, Lee CG, Zheng $T$, et al. New insights into the pathogenesis of asthma. J Clin Invest 2003; 111: 291-297.

2 Wanner A, Salathe M, O'Riordan TG. Mucociliary clearance in the airways. Am J Respir Crit Care Med 1996; 154: 1868-1902.

3 Knowles MR, Boucher RC. Mucus clearance as a primary innate defense mechanism for mammalian airways. J Clin Invest 2002; 109: 571-577.

4 Mall MA. Role of cilia, mucus, and airway surface liquid in mucociliary dysfunction: lessons from mouse models. J Aerosol Med Pulm Drug Deliv 2008; 21: 13-24.

5 Wills-Karp M, Luyimbazi J, Xu X, et al. Interleukin-13: central mediator of allergic asthma. Science 1998; 282: 2258-2261.

6 Zhu Z, Homer RJ, Wang Z, et al. Pulmonary expression of interleukin-13 causes inflammation, mucus hypersecretion, subepithelial fibrosis, physiologic abnormalities, and eotaxin production. J Clin Invest 1999; 103: 779-788.

7 Kuperman DA, Huang X, Koth LL, et al. Direct effects of interleukin-13 on epithelial cells cause airway hyperreactivity and mucus overproduction in asthma. Nat Med 2002; 8: 885-889.

8 Danahay H, Atherton H, Jones G, et al. Interleukin-13 induces a hypersecretory ion transport phenotype in human bronchial epithelial cells. Am J Physiol Lung Cell Mol Physiol 2002; 282: L226-L236.

9 Galietta LJ, Pagesy P, Folli C, et al. IL-4 is a potent modulator of ion transport in the human bronchial epithelium in vitro. J Immunol 2002; 168: 839-845.

10 Mall M, Grubb BR, Harkema JR, et al. Increased airway epithelial $\mathrm{Na}^{+}$absorption produces cystic fibrosis-like lung disease in mice. Nat Med 2004; 10: 487-493.

11 Anderson MP, Gregory RJ, Thompson S, et al. Demonstration that CFTR is a chloride channel by alteration of its anion selectivity. Science 1991; 253: 202-205.

12 Caputo A, Caci E, Ferrera L, et al. TMEM16A, a membrane protein associated with calcium-dependent chloride channel activity. Science 2008; 322: 590-594.

13 Rock JR, O'Neal WK, Gabriel SE, et al. Transmembrane protein 16A (TMEM16A) is a $\mathrm{Ca}^{2+}$-regulated $\mathrm{Cl}^{-}$secretory channel in mouse airways. J Biol Chem 2009; 284: 14875-14880.

14 Mehlhop PD, van de RM, Goldberg AB, et al. Allergen-induced bronchial hyperreactivity and eosinophilic inflammation occur in the absence of IgE in a mouse model of asthma. Proc Natl Acad Sci USA 1997; 94: 1344-1349.

15 Kuperman D, Schofield B, Wills-Karp M, et al. Signal transducer and activator of transcription factor 6 (Stat6)-deficient mice are protected from antigen-induced airway hyperresponsiveness and mucus production. J Exp Med 1998; 187: 939-948.

16 Tachdjian R, Mathias C, Al Khatib S, et al. Pathogenicity of a disease-associated human IL-4 receptor allele in experimental asthma. J Exp Med 2009; 206: 2191-2204.

17 Zhou Z, Treis D, Schubert SC, et al. Preventive but not late amiloride therapy reduces morbidity and mortality of lung disease 
in $\beta \mathrm{ENaC}$-overexpressing mice. Am J Respir Crit Care Med 2008, 178: $1245-1256$

18 Grubb BR, Paradiso AM, Boucher RC. Anomalies in ion transport in CF mouse tracheal epithelium. Am J Physiol 1994; 267: C293-C300

19 Mall M, Bleich M, Greger R, et al. The amiloride inhibitable $\mathrm{Na}^{+}$ conductance is reduced by CFTR in normal but not in cystic fibrosis airways. J Clin Invest 1998; 102: 15-21.

20 Mall M, Gonska T, Thomas J, et al. Activation of ion secretion via proteinase-activated receptor-2 in human colon. Am J Physiol Gastrointest Liver Physiol 2002; 282: G200-G210.

21 Zimmermann N, Mishra A, King NE, et al. Transcript signatures in experimental asthma: identification of STAT6-dependent and -independent pathways. J Immunol 2004; 172: 1815-1824.

22 Kerem E, Bistritzer T, Hanukoglu A, et al. Pulmonary epithelial sodium-channel dysfunction and excess airway liquid in pseudohypoaldosteronism. N Engl J Med 1999; 341: 156-162.

23 Matsui H, Grubb BR, Tarran R, et al. Evidence for periciliary liquid layer depletion, not abnormal ion composition, in the pathogenesis of cystic fibrosis airways disease. Cell 1998; 95: 1005-1015.

24 Regnis JA, Robinson M, Bailey DL, et al. Mucociliary clearance in patients with cystic fibrosis and in normal subjects. Am J Respir Crit Care Med 1994; 150: 66-71.

25 Mall MA, Harkema JR, Trojanek JB, et al. Development of chronic bronchitis and emphysema in $\beta$-epithelial $\mathrm{Na}^{+}$channel-overexpressing mice. Am J Respir Crit Care Med 2008; 177: 730-742.

26 Lay JC, Alexis NE, Zeman KL, et al. In vivo uptake of inhaled particles by airway phagocytes is enhanced in patients with mild asthma compared with normal volunteers. Thorax 2009; 64 313-320.

27 Messina MS, O'Riordan TG, Smaldone GC. Changes in mucociliary clearance during acute exacerbations of asthma. Am Rev Respir Dis 1991; 143: 993-997.

28 Innes $\mathrm{AL}$, Carrington SD, Thornton DJ, et al. Ex vivo sputum analysis reveals impairment of protease-dependent mucus degradation by plasma proteins in acute asthma. Am J Respir Crit Care Med 2009; 180: 203-210

29 Verdugo P. Mucin exocytosis. Am Rev Respir Dis 1991; 144: S33-S37.

30 Dunnill MS. The pathology of asthma, with special reference to changes in the bronchial mucosa. J Clin Pathol 1960; 13: 27-33.

31 Garcia-Caballero A, Rasmussen JE, Gaillard E, et al. SPLUNC1 regulates airway surface liquid volume by protecting $\mathrm{ENaC}$ from proteolytic cleavage. Proc Natl Acad Sci USA 2009; 106: 1141211417

32 Blouquit S, Regnier A, Dannhoffer L, et al. Ion and fluid transport properties of small airways in cystic fibrosis. Am I Respir Crit Care Med 2006; 174: 299-305

33 Mall M, Wissner A, Gonska T, et al. Inhibition of amiloridesensitive epithelial $\mathrm{Na}^{+}$absorption by extracellular nucleotides in human normal and cystic fibrosis airways. Am J Respir Cell Mol Biol 2000; 23: 755-761.

34 Rollins BM, Burn M, Coakley RD, et al. A2B adenosine receptors regulate the mucus clearance component of the lung's innate defense system. Am J Respir Cell Mol Biol 2008; 39: 190-197.

35 Lazarowski ER, Boucher RC. Purinergic receptors in airway epithelia. Curr Opin Pharmacol 2009; 9: 262-267. 